\title{
Aleitamento: mulheres trabalhadoras contemporâneas de uma universidade privada na Zona Oeste, Rio de Janeiro
}

Breastfeeding: lactation: contemporary working women at a private university in the West Zone, Rio de Janeiro

Lactancia materna: lactancia: mujeres trabajadoras contemporáneas en una universidad privada de la Zona Oeste, Río de Janeiro

Tuany Brito Guedes de Sousa ORCID: https://orcid.org/0000-0002-4491-0570

Universidade Castelo Branco, Brasil E-mail: tuanybrito.rj@gmail.com Carolina Almeida Lopes ORCID: https://orcid.org/0000-0002-1628-3522 Universidade Castelo Branco, Brasil E-mail: carol.2016171627@gmail.com

Deborah Barbosa Rosendo Alves ORCID: https://orcid.org/0000-0002-4713-6672 Universidade Castelo Branco, Brasil E-mail: enfdeborahbraf@gmail.com

Maria Regina Bernardo da Silva ORCID: https://orcid.org/0000-0002-3620-3091 Centro Universitário CBM, Brasil E-mail: m.regina2000@bol.com.br

Lidiane Rossato Deckmann Nogueira ORCID: https://orcid.org/0000-0002-5913-1334 Universidade Nossa Senhora de Fátima, Brasil E-mail:lidydeck@gmail.com Thaís Araujo Vianna ORCID: https://orcid.org/0000-0002-0892-5898 Universidade Castelo Branco, Brasil E-mail: thais.pnk@gmail.com

\begin{abstract}
Resumo
Objetivo: Descrever as estratégias realizadas pela mulher contemporânea para a manutenção do aleitamento materno após o retorno ao trabalho. Método: Tratou-se de uma pesquisa de campo, com abordagem qualitativa, de caráter exploratório, do tipo pesquisa de campo em Universidade privada da zona oeste do Rio de Janeiro. Resultados: Foram entrevistadas 13 mulheres, Jovens, casadas, 15 anos de escolaridade com 1 filho. Observou-se a fragilidade no processo de adaptação e retorno ao trabalho devido pouco conhecimento dessas mulheres em relação ao aleitamento, escassa orientação no pré-natal, apoio familiar sofrível, falta de local adequado para guarda e retirada de leite. Considerações: O presente estudo, permite conhecer a demonstração da atuação dos enfermeiros no papel fundamental do esclarecimento sobre possíveis dúvidas em relação ao período lactário, sendo que o aleitamento materno exclusivo, envolve questões sociais, biológicas e psicológicas, que devem ser acompanhadas desde o pré-natal, propiciando as mães o desenvolvimento da autoconfiança em amamentar e na expertise de superar dificuldades com o seu retorno ao trabalho.
\end{abstract}

Palavra-chave: Aleitamento; Mulheres no mercado de trabalho; Saúde materno-infantil.

\begin{abstract}
Objective: To describe the strategies performed by contemporary women to maintain breastfeeding after returning to work. Method: It was field research, with a qualitative approach, of exploratory character, of the field research type in a private university in the west side of Rio de Janeiro. Results: 13 women were interviewed, young, married, 15 years of schooling with 1 child. Weakness in the process of adaptation and return to work was observed due to these women's lack of knowledge about breastfeeding, little guidance in prenatal care, poor family support, lack of adequate place for storing and withdrawing milk. Considerations: This study allows knowing the demonstration of the nurses' role in the fundamental role of clarifying possible doubts regarding the lactation period, and exclusive breastfeeding involves
\end{abstract}


social, biological and psychological issues, which must be monitored from the pre- -natal, providing mothers with the development of self-confidence in breastfeeding and in the expertise to overcome difficulties with their return to work. Keywords: Breastfeeding; Women in the labor market; Maternal and child health.

\begin{abstract}
Resumen
Objetivo: Describir las estrategias que realizan las mujeres contemporáneas para mantener la lactancia materna luego de su reincorporación al trabajo. Método: Fue una investigación de campo, con enfoque cualitativo, de carácter exploratorio, del tipo investigación de campo en una universidad privada del occidente de Río de Janeiro. Resultados: se entrevistaron 13 mujeres, jóvenes, casadas, 15 años de escolaridad con 1 hijo. Se observó debilidad en el proceso de adaptación y reincorporación al trabajo debido a la falta de conocimiento de estas mujeres sobre la lactancia materna, poca orientación en el cuidado prenatal, escaso apoyo familiar, falta de lugar adecuado para almacenar y extraer la leche. Consideraciones: Este estudio permite conocer la demostración del rol de las enfermeras en el rol fundamental de aclarar posibles dudas sobre el período de lactancia, y la lactancia materna exclusiva involucra aspectos sociales, biológicos y psicológicos, los cuales deben ser monitoreados desde el prenatal, brindando a las madres con el desarrollo de la confianza en sí mismos en la lactancia materna y en la experiencia para superar las dificultades con su regreso al trabajo.
\end{abstract}

Palabras clave: Amamantamiento; Mujeres en el mercado laboral; Salud maternal e infantil.

\title{
1. Introdução
}

A Organização Mundial da Saúde (OMS) preconiza que a criança seja nutrida exclusivamente com o leite materno até os seis meses de idade, isso acarretará consigo impactos positivos para a saúde do recém-nascido, assim também com para sua saúde durante sua vida adulta (Alves, 2018).

Essas crianças que recebem o aleitamento materno exclusivo (AME) nos seus primeiros meses de vida têm mais probabilidade de não evoluírem para o acometimento de doenças crônicas não transmissíveis durante sua vida, pois o leite materno possui propriedades eficientes para que aconteça a maturidade fisiológica da criança, assim também como propriedades eficientes para prevenção de patologias, que são necessárias nos primeiros meses de idade do lactente (Lopes, 2018).

O leite materno também garante à criança que ela cresça com menos riscos de hipertensão, diabetes e colesterol alto, por exemplo, trazendo uma evolução para a saúde pública como um todo. Amamentar até os seis meses diminui o risco de câncer de mama na mulher e ajuda no pós-parto, já que o útero se contrai e volta ao tamanho normal mais rapidamente. Protegendo o AM (aleitamento materno) reduz a morbimortalidade materna e infantil, aumenta-se o quociente de inteligência infantil e o desempenho escolar, o que contribui de forma indireta para a redução da pobreza no país (Silva, 2017).

Por lei (CLT396), a mãe que amamenta, tem direito de ter 2 intervalos de 30 minutos cada, para amamentar seu bebê até o 60 mês, podendo esse prazo ser ampliado mediante parecer médico. Porém, na maioria das vezes a trabalhadora não tem como conciliar o trabalho com a amamentação exclusiva por seis meses, tanto por conta de licença maternidade obrigatória ser de apenas quatro meses, como também, por muitas vezes, trabalhar longe de casa e os intervalos de 30 minutos serem inviáveis para amamentar. Esse quadro gera o aumento do desmame precoce, que diminui os benefícios do aleitamento materno exclusivo (Brasileiro,2010). O investimento em licença-maternidade pode trazer impactos positivos para a saúde da mulher e da criança, e para a economia de um país (Rollins, 2016).

$\mathrm{O}$ curto período da licença maternidade e a falta de estrutura dos locais de trabalho para a retirada e armazenamento adequados do leite materno, podem estar relacionados às taxas abaixo do recomendado pela Organização Mundial da Saúde (Brow, 2017).

O desmame precoce tem causas multifatoriais, como o pouco incentivo ao aleitamento materno, a desinformação durante o pré-natal, o acúmulo de leite ou dificuldade de amamentar, a condição da mulher que trabalha fora de casa. É cada vez maior o número de mulheres que trabalham fora de casa, e a empresa dificilmente oferece condições para ela manter o aleitamento após o término da licença maternidade (Guex, 2020). 
Desse modo, percebe-se a família como o pilar fundamental para ações de promoção e incentivo ao aleitamento materno, já que as experiências da mesma são muito valorizadas e respeitadas, especialmente nos cuidados com a criança, tendo em vista que a maioria das mulheres que retornam as suas atividades laborais deixam seus filhos salvaguardados por familiares próximos (Teixeira, 2017).

Diante deste cenário o enfermeiro torna-se indispensável ao acolhimento da mulher contemporânea, em seu ciclo gravídico-puerperal e ao longo do desenvolvimento da criança, realizando as intervenções necessárias para que ela possa estar mais confortável e segura na adaptação do aleitamento materno no que tange ao binômio mãe e filho e seu retorno ao trabalho (Nascimento, 2016).

Todos esses benefícios para a saúde do bebê e da mãe fazem com que a Organização Mundial da Saúde e o Ministério da Saúde recomendem o aleitamento materno até os dois anos ou mais e exclusivo durante seus os primeiros seis meses de vida, ou seja, sem chás, água ou qualquer outro líquido ou alimento. Após os seis meses o leite materno continua sendo importante para a criança, mas nesse momento ela já deve começar a receber outros alimentos saudáveis.

A relevância da pesquisa é demonstrar, que a amamentação é de vital importância para o desenvolvimento nutricional e o vínculo mãe-filho. Requer disponibilidade materna para ser praticada com eficácia e dedicação no primeiro semestre de vida da criança, necessita de apoio familiar e suporte no ambiente de trabalho. Observa-se, que mulher trabalhadora, após licença maternidade, se depara com a difícil estratégia de conciliar o Aleitamento Materno Exclusivo e o trabalho remunerado. Objetivo: Identificar como as mulheres contemporâneas conseguem manter o aleitamento materno exclusivo após o retorno ao trabalho.

\section{Metodologia}

Tratou-se de uma pesquisa de campo, com abordagem qualitativa, de caráter exploratório, do tipo pesquisa de campo em Universidade privada da zona oeste do Rio de Janeiro. A abordagem qualitativa teve como foco a busca de informações relacionadas à subjetividade dos sujeitos, captando os significados e significações expressas acerca dos fenômenos em estudo. Este tipo de abordagem entende o indivíduo como ser único, com seus valores e significados (Minayo, 2011).

A pesquisa foi desenvolvida em uma Universidade privada na zona oeste do Rio de Janeiro. A população de estudo consiste em um grupo de 13 mulheres trabalhadoras da administração da Universidade. Como critérios de inclusão do estudo foram mulheres trabalhadoras maiores de 18 anos até 40 anos em idade fértil com filhos. Como critério de exclusão, mulheres que não respondessem todas as perguntas. Utilizou-se somente $30 \%$ das trabalhadoras, devido à dificuldade no momento da pandemia de entrevistar essas mulheres. Foram utilizados os protocolos de distanciamento social, máscaras e ambiente aberto durante as entrevistas devido à pandemia de covid 19.

A entrevista utilizada foi semiestruturada, que segundo MINAYO, "combina perguntas fechadas e abertas, em que o entrevistado teve a possibilidade de discorrer sobre o tema em questão sem se prender à indagação formulada". A entrevista foi realizada no período de março e abril de 2021, em local reservado que tinha na universidade, foi feito contato prévio com a chefia da administração para realizar a pesquisa de acordo com a disponibilidade da rotina delas. A coleta de dados iniciou-se após o aceite e assinatura pelos sujeitos da pesquisa do Termo de Consentimento Livre e Esclarecido (TCLE).

Seguindo ainda o pensamento de Bardin, a análise de conteúdo foi dívida em três momentos, que são: a pré-análise, que são definidos os documentos que foram submetidos a análise; a exploração do material e tratamento dos resultados que se dá pela transformação dos dados brutos em uma estrutura organizada que permite descrever as características do conteúdo; e a inferência e a interpretação. Com as respostas obtidas, formaram-se subdivisões do tema que foram definidos.

O Termo de Consentimento Livre e Esclarecido foi assinado por cada participante, atendendo ao que pede a Resolução 466/12. Após resultado do comitê de ética CER Nº.536.661. Para reservar a sua identidade, os participantes desta pesquisa foram identificados por letra e números. 


\section{Resultados e Discussão}

A estratégia da mulher contemporânea para a manutenção do aleitamento materno é a questão de manter uma rotina, realizar uma adequação nas suas atividades para fins de realizar a ordenha e armazenamento do leite, sendo após ofertado por um familiar ou cuidador. Muitas mulheres têm a questão de morarem próximo ao trabalho, podendo assim no horário do almoço ir para casa e poder amamentar o seu filho. Quando retornam ao trabalho a mulher conversa com a chefia para fins de ter uma adequação e ajuste no seu horário de trabalho, podendo assim ser liberada mais cedo para poder retornar a sua casa e manter a amamentação. Outras mulheres trabalham apenas um turno, podendo assim ter um tempo com os filhos e no período que estão ausentes o familiar ou o cuidador ofertar o leite que essa mãe deixou armazenado.

Foram feitas 13 entrevistas com trabalhadoras que atuam em uma Universidade na zona oeste com idades de 18 a 40 anos de idade.

Quadro 1: Perfil socioeconômico e número de gravidez das mulheres trabalhadoras de uma Universidade na zona oeste, Rio de Janeiro. Brasil, 2021.

\begin{tabular}{|c|c|c|c|c|c|c|c|}
\hline $\mathbf{N}^{\mathbf{o}}$ & IDADE & $\begin{array}{c}\text { ESTADO } \\
\text { CIVIL }\end{array}$ & FILHOS & ESCOLARIDADE & RENDA FAMILIAR & $\begin{array}{c}\text { ÚLTIMO } \\
\text { PARTO }\end{array}$ & GRAVIDEZ \\
\hline 01 & Acima de 30 anos & Casada & Três & Superior Completo & 3 a 4 Salários & 7 a 9 anos & Mais de Três \\
\hline 02 & Acima de 30 anos & Solteira & $\mathrm{Um}$ & Médio Completo & 1 a 2 Salários & 10 anos & Duas \\
\hline 03 & Acima de 30 anos & Casada & Dois & Superior Completo & 3 a 4 Salários & 4 a 6 anos & Três \\
\hline 04 & Acima de 30 anos & Solteira & Um & Superior Completo & 3 a 4 Salários & 1 a 3 anos & Uma \\
\hline 05 & 21 a 25 anos & Solteira & Um & Superior Incompleto & 1 a 2 Salários & 1 a 3 anos & Uma \\
\hline 06 & 18 a 20 anos & Casada & Dois & Superior Incompleto & 1 a 2 Salários & 4 a 6 anos & Duas \\
\hline 07 & Acima de 30 anos & Casada & Dois & Superior Completo & 1 a 2 Salários & $\begin{array}{c}10 \text { anos ou } \\
\text { mais }\end{array}$ & Uma \\
\hline 08 & Acima de 30 anos & Divorciada & Dois & Superior Completo & 1 a 2 Salários & $\begin{array}{c}10 \text { anos ou } \\
\text { mais }\end{array}$ & Duas \\
\hline 09 & 26 a 30 anos & Casada & Um & Superior Incompleto & 1 a 2 Salários & 1 a 3 anos & Três \\
\hline 10 & Acima de 30 anos & Casada & Dois & Superior Completo & Acima de 4 Salários & 4 a 6 anos & Duas \\
\hline 11 & 26 a 30 anos & Casada & Um & Médio Completo & 1 a 2 Salários & 1 a 3 anos & Uma \\
\hline 12 & Acima de 30 anos & Casada & Um & Superior Incompleto & 3 a 4 Salários & 1 a 3 anos & Uma \\
\hline 13 & Acima de 30 anos & Casada & Um & Superior Completo & Acima de 4 Salários & 1 a 3 anos & Uma \\
\hline
\end{tabular}

Fonte: Autores (2021).

Observa-se no Quadro 1 foram entrevistadas 13 mulheres, na sua maioria jovens 69,2\% (9) tem acima de 30 anos, em seguida 15,3\% (2) de 26 a 30 anos, quanto ao estado civil 69,2\% (9) informaram ser casada, mostrando que as mulheres estão à frente do trabalho cooperando com seus respectivos companheiros na parte financeira, quanto ao número de gestações na sua 
maioria informaram ter um filho $53,8 \%$ (7) e dois filhos $38,4 \%$ observando que as mulheres estão preocupadas com o planejamento familiar reduzindo as gestações, quanto tempo do último parto 53,8\% (7) informaram ter de 1 a 3 anos, 30,7\% (4) com 10 anos, quanto a renda familiar 46,15\% (6) de 1 a 2 salários e 30,7\% (4) de 3 a 4 salários, vemos que as mulheres estão contribuindo para aumento da renda familiar e melhora da qualidade de vida e quanto a escolaridade na sua maioria informaram $61,5 \%$ (8) ter superior completo, mostrando a preocupação em melhorar nível sociocultural.

Segundo Colombo e Santana (2018) relatou que na sua pesquisa a maioria das puérperas que estavam amamentando exclusivamente estudaram por até oito anos. Esse resultado corrobora com estudos que relatam maior nível de escolaridade como percursor de maior acesso à informação e motivação referente às vantagens da amamentação, resultando em maior duração da amamentação.

Quadro 2: Identificação quanto ao número de gestações, onde foi acompanhada no pré-natal e quanto a amamentação em mulheres trabalhadoras de uma Universidade da zona oeste Rio de Janeiro. Brasil, 2021.

\begin{tabular}{|c|c|c|}
\hline TIPO DE PARTO & Número & $\%$ \\
\hline Cesárea & 11 & 84,6 \\
\hline Normal & 05 & 38,4 \\
\hline ONDE FEZ PRÉ NATAL & Número & $\%$ \\
\hline Público & 08 & 61,5 \\
\hline Privado & 07 & 53,8 \\
\hline GRAVIDEZ ACOMPANHADA POR & Número & $\%$ \\
\hline Médico & 08 & 61,5 \\
\hline Enfermeiro & 02 & 15,3 \\
\hline Enfermeiro e Médico & 03 & 23,07 \\
\hline AMAMENTOU SEUS FILHOS & Número & $\%$ \\
\hline $\operatorname{Sim}$ & 09 & 69,2 \\
\hline Não & 04 & 30,7 \\
\hline TEMPO DE LICENÇA MATERNIDADE & Número & $\%$ \\
\hline 02 Meses & 02 & 15,3 \\
\hline 03 Meses & 01 & 7,6 \\
\hline 04 Meses & 07 & 53,8 \\
\hline 06 Meses & 02 & 15,3 \\
\hline
\end{tabular}

Fonte: Autores (2021).

Segundo Quadro 2 Observou-se 84,6\% (11) tiveram parto cesárea, observando que o número de cesárea tem aumentado substancialmente e 38,4\% (5) informaram ter tido parto normal, sendo este parto fisiológico para as condições da mãe e bebê, quanto ao local onde fez o pré-natal 61,5\% (8) ocorreram em hospital público, devido as questões financeiras muitas mulheres optam pelo público. 53,8\% (7) foram em hospital privado. Em relação ao tempo de licença maternidade 53,8\% (7) tiveram 04 meses de licença, 15,3\% (2) 02 meses, 7,6\% (1) 03 meses, 15,3\% (2) tiveram 06 meses de licença, observando que ainda encontramos mulheres que retornaram antes do previsto da licença, e que segundo direitos desde 1988 da constituição, a licença maternidade tem a duração de 120 dias, podendo entrar de licença 28 dias antes do parto. 
Observa-se que 69,2\% (9) entrevistadas informaram que amamentaram seus filhos. Dados da OMS revelam que a quantidade de crianças em AME até seis meses de idade em todo o mundo, é de apenas aproximadamente um terço. O sucesso do aleitamento não depende apenas de tempo disponível para a prática, há vários outros motivos que interferem como: problemas mamários, influências sociais, estética, dor, entre outros. Porém, o estímulo à amamentação deve levar em consideração todas as necessidades e dificuldades que envolvem cada mulher, cabendo à mãe decidir o que será melhor para seu filho (Callou, 2014).

A licença maternidade brasileira vai ao encontro com a recomendação da OMS sobre o AME de 120 dias a 180 dias pós-parto. A mulher antes de terminar a licença maternidade já tem que introduzir novos alimentos na alimentação da criança, para quando houver o retorno ao trabalho está já estar acostumada sem o leite materno. O intervalo de 30 minutos para amamentar nem sempre é viável a todas as mulheres, pois muitas trabalham longe de casa e não possuem locais adequados para amamentação ou creche perto ou dentro da empresa (Callou, 2014).

No Quadro 2 apesar do pré-natal da maioria das entrevistadas ser feito por médico obstetra, não observamos orientação em relação ao aleitamento, pesquisa de Osis et al. (2014) encontrou relatos houve participantes que disseram que o obstetra não influencia em nada a decisão das mulheres em amamentar porque, na verdade, não orienta sobre isso durante o pré-natal. Mostrando que o obstetra por ser um profissional muito acreditado pelas mulheres, deveriam desempenhar esse papel também de conselheiro da amamentação (Demitto, 2010).

A pesquisa de Demitto (2010), encontramos relato importantes que nas consultas de pré-natal deve ser fornecida orientações por meio de informações dos profissionais da saúde, em especial pelo enfermeiro, dos benefícios do AM, das técnicas corretas da amamentação, com a finalidade de aumentar a habilidade e confiança dessas mulheres. Sabe-se que o enfermeiro é um cuidador que faz parte das consultas de enfermagem no pré-natal orientação e demonstração de técnicas de higiene e aleitamento, para melhor compreensão as gestantes na manutenção da amamentação.

\section{Categorização}

\section{Foram divididas em quatro categorias a seguir:}

\section{Categoria 1: Orientação sobre aleitamento materno durante a gravidez}

Neste eixo, o desejo da mulher em amamentar, o compromisso e determinação com a saúde do lactente, atitudes e esforços de cada mãe, meta a ser alcançada, interesse e planejamento das ações após o nascimento ainda durante o pré-natal foram os principais sentimentos citados que auxiliam na manutenção/duração da amamentação após o retorno ao trabalho.

\section{Falas das entrevistadas:}

A 12... Fiz o pré-natal no postinho perto da minha casa e durante o pré-natal tive orientação com enfermeiro sobre os cuidados com a mama, posição de amamentar e importância de amamentar; acho importante amamentar.

A 08...Fui orientada quanto aos cuidados com o bico do peito, insistência para a amamentação, e pegar sol no bico e passar óleo e que é importante para o bebê.

A 13...Na rede privada tive poucas informações. Na rede pública tive orientações como realizar e manter a amamentação, pega correta e cuidados com a mama.

Observa-se na pesquisa que a Unidade Primaria de Saúde tem preocupação nos cuidados e orientação do aleitamento as gestantes, e que o enfermeiro é um profissional voltado para educação, saúde, prevenção de agravos e que diante de orientações sobre a amamentação, ela fica esclarecida em relação a sua importância materno infantil. 
Recomenda-se a amamentação exclusiva, de acordo com a OMS, até os seis meses de vida, pois, após esse período, ela deverá ser complementada com alimentos líquidos e sólidos. Relacionam-se, contudo, vários fatores à dificuldade de amamentar ou à suspensão precoce, entre eles, a falta de informação da mãe, aspectos sociais, culturais, mitos, crenças e políticos que interferem no processo de amamentação (Sardinha, 2019).

Diante dos benefícios do leite materno, o incentivo e o apoio ao aleitamento materno devem ser contínuos para a promoção de conhecimento adequado, manutenção e motivação para sua prática efetiva. Para tal, os profissionais de saúde devem identificar, esclarecer as dúvidas, dificuldades relacionadas à amamentação e sendo assim contribuindo para uma assistência que apoie a mulher para que ela alcance o êxito desejável de amamentar (Vargas, 2016).

Destaca-se que a assistência pré-natal é um conjunto de procedimentos clínicos e educativos com a finalidade de promover a saúde e identificar, antecipadamente, problemas que possam resultar em risco para a saúde da gestante e do concepto (Barreira, 2014).

\section{Relatos sobre a ausência de orientação de AM por profissionais da saúde}

Pode-se dificultar, pela não promoção do aleitamento materno no pré-natal, a segurança das mães na prática do aleitamento materno e na promoção da saúde do recém-nascido, por isso, tais ações, executadas pelo profissional enfermeiro, têm grande relevância na atenção pré-natal (Silva, 2014).

Os enfermeiros são profissionais fundamentais para a promoção e proteção da saúde dos indivíduos, em relação as grávidas e as puérperas, deve ter participação desde o pré-natal, com ações educativas para a gestante e familiares, propiciando o seu acolhimento e a escuta ativa, para que ela seja a responsável pelo cuidado, destarte favorecendo a prática do aleitamento materno exclusivo. Os enfermeiros devem estar cientes de sua importância no processo de cuidado e educação, atuando com interesse, responsabilidade e compromisso com toda população conforme as diretrizes do exercício profissional, ideal de atuação (Costa, 2018).

A 09, A 11...Tive pouca orientação de aleitamento no pré-natal acho que deveria ter mais orientações, só falaram que é importante amamentar.

\section{A 02...Não teve orientações.}

Demonstraram-se, em um estudo no Reino Unido, alguns fatores que estimulam o desmame antes do sexto mês de vida: primeiro, relacionando ao modo de vida atual, em que as mães precisam trabalhar e, assim, a maioria retorna logo ao emprego e começa a oferecer leites industrializados para o bebê, influenciada, também, pela mídia, que mostra que esses produtos são muito positivos para a saúde da criança (Sardinha, 2019).

Confia-se que o AM, além de trazer todos os benefícios possíveis para a criança, também ocasiona benefícios para a mulher, família e sociedade. Necessita-se, assim, para a promoção do AM, que no pré-natal, profissionais capacitados sobre o tema possam promover de maneira correta, abordando sem ofensas e ou constrangimento a mulher, levando em consideração as suas experiências de vida e trocando saberes sobre o tema (Davanzo, 2015).

A 05...Não teve orientação, a mãe aconselhou a beber água, leite, tomar mingau e suco de laranja.

No estudo de Fragoso e Fortes (2011),7,85\% das mães apontaram o leite fraco como motivo para introdução precoce de alimentos da dieta do bebê. O mito do leite fraco é um dos maiores motivos para o desmame precoce, isso ocorre devido à pouca orientação recebida pelas mães e muitas vezes pela pouca experiência. 
Identificou-se no estudo de Sardinha DM, Maciel DO et al. (2019) na dinâmica sobre mitos e verdades, que as gestantes acreditam em muitos mitos sobre a temática, o que pode favorecer o desmame precoce, o baixo peso, maiores chances de adoecer etc. Levanta-se que o primeiro mito é o do leite fraco, que só ajuda no desmame precoce e pode estimular a prática da amamentação cruzada, que a maioria das gestantes, na dinâmica, acreditava ser benéfico (Sardinha, 2019).

Esses mitos e informações errôneas sobre o AM levam a amamentação ineficaz ao bebê, daí a importância da informação e comunicação ser coerente para que o bebê tenha um aleitamento adequado, eficaz e a mãe também tenha benefícios com o aleitamento.

\section{Categoria 2: Orientação do armazenamento de leite materno}

É de suma importância a nutriz saber como retirar leite e armazenar principalmente as mulheres trabalhadoras, já que no Brasil as mulheres ficam 120 dias de licença, retornando as suas atividades ainda no período de aleitamento exclusivo. Mas observa-se que poucas mulheres tiveram essa recomendação.

A 01, A 03...Os médicos me orientaram retirar o leite antes de sair para trabalhar e colocar em recipientes higienizados e assim foi feito.

\section{Relatos sobre falta de orientação sobre armazenamento do leite materno}

Aconteceu um número substancial de falta de orientação sobre o armazenamento de leite materno, observa-se a necessidade de maiores informações sobre armazenamento que contribuiria muito para melhorar a manutenção do aleitamento.

A 11, A 12... Não tive orientação sobre isso, mas quando precisei fui à unidade de saúde perguntar e me orientaram.

A 13...Tive poucas orientações, mas por ser profissional da saúde para mim foi tranquilo esse processo, por já ter conhecimento e experiência sobre como realizar a ordenha e o armazenamento do leite materno.

A 02, A 06, A 08, A 09...Não teve orientação nem da enfermagem, nem durante o pré-natal, nem durante a internação na maternidade e nem na alta e nem acompanhamento da puericultura.

Ações educacionais individuais ou em grupo são ferramentas necessárias para realizar mudanças a respeito das percepções referentes à amamentação, respeitando sempre a individualidade de cada mulher. Desse modo, uma equipe multiprofissional tem papel fundamental para impedir barreiras e preocupações maternas, diminuindo as incertezas e medos e, consequentemente, repará-las para continuar a amamentar após a retomada de suas atividades ao trabalho (Silva, 2014).

Existem relatos de experiências negativas referente a retirada de leite no trabalho Peres (2015) afirma que é comum as mulheres vivenciarem o descumprimento de aspectos previstos na legislação e passarem por constrangimentos, tanto no ambiente de trabalho quanto no ambiente escolar, sem estrutura mínima para retirada do leite e mesmo para o esvaziamento das mamas. Isto soma-se a cenários de trabalho desgastante, longos percursos para deslocamento ao trabalho, falta de acesso a creche e pouco apoio da família para atividades de trabalho doméstico. Observando a necessidade de orientação a essa mulher que está amamentando nos espaços do trabalho e de maior flexibilização do empregador com ambiente favorável à retirada do leite e acondicionamento seguro (Gomes, 2021).

Apesar da instituição onde ocorreu a pesquisa ser de ensino, não houve nenhuma habilidade voltada para o cuidado e flexibilidade para as mulheres durante o período de amamentação no seu retorno ao trabalho. 


\section{Categoria 3: Ajuda de algum familiar ou alguém no retorno ao seu trabalho}

Quando a mulher retorna para o seu trabalho, se ela terá ajuda em relação aos cuidados com o bebê, deixa essa mãe mais tranquila, trabalhando com confiança e sem medo em relação aos cuidados com o bebê e a creche também é um facilitador para essa mãe.

Contudo, a família representa a rede de apoio primária de todo e qualquer indivíduo. É um sistema de relações contínuas e interligadas, estabelecida por meio de uma rede própria de cuidar pautada em valores, crenças e conhecimentos. Desse modo, percebe a rede de apoio como estratégia para ações de incentivo ao aleitamento materno é fundamental para que a mulher possua êxito na realização da amamentação (Barreira, 2014).

\section{A 03...Para retornar aо meu emprego precisei de creche para cuidar do meu filho.}

A 11...Voltei a trabalhar meu bebê ficava com minha mãe só confiava nela, e deixava leite congelado e ela tomava, mas almoçava e comia frutas.

A 12... Quando voltei a trabalhar o meu bebê ficava com a empregada, deixava cinco mamadeiras para ser oferecida durante o dia, ficava com a empregada que cuidava muito bem.

De tal modo, a principal fonte de captação das puérperas é a Estratégia de Saúde da (ESF), cabendo aos profissionais de saúde ressaltar a importância do AME, estimular a mulher desde o pré-natal a aceitar essa prática, e tentar reduzir ao máximo os fatores que interferem no sucesso da amamentação através de apoio, informações e assistência de qualidade a mãe, a criança e a família (Callou, 2014).

É extremamente importante a mulher ter apoio seja da família, amigos, creche, isso fortalece essa mãe, coopera e favorece na manutenção do aleitamento.

\section{Categoria 4: O trabalho facilitou durante a amamentação até os seis meses}

As mulheres encontram muitos desafios para manutenção do aleitamento materno. Um deles é o retorno ao trabalho, já que muitas precisam retornar antes dos bebês completarem seis meses. Sendo este um dos fatores de interrupção da amamentação. É preciso equilibrar o retorno ao trabalho, a vida pessoal e ter um bom planejamento para garantir que seu bebê continue se beneficiando do leite materno. Muitos motivos podem levar ao desmame como: não ter o apoio do empregador, não contar com uma estrutura no trabalho que possibilite a ordenha, falta de apoio familiar, pouca informação, entre outros (Barreira, 2014).

Em muitas situações a ordenha de leite materno pode ser necessária, e para manter o aleitamento materno ao retorno ao trabalho, esta técnica é a forma de maior legitimidade e credibilidade, adotada como a primeira prática para a continuidade do aleitamento materno, porém esta técnica deve ser empregada dentro de um processo de confiança e vinculo estabelecido entre a mulher e o profissional de saúde, onde juntos estabeleceram cuidados, esclarecimentos de dúvidas, alcançando assim menos danos possível no processo de adaptação e manutenção do aleitamento materno (Callou, 2014).

A 11...Eu voltei a trabalhar com cinco meses entrava uma hora mais tarde, deixava o bebê mamado, comia fruta $10 \mathrm{~h}$ e almoçava $12 \mathrm{~h}$ depois a tarde mamava as mamadeiras que deixava. Não teve problemas porque chegava $17 \mathrm{~h} 20 \mathrm{~h}$ em casa aí começava a mamar em mim. 
A 12...Durante o período que eu retornei podia sair uma hora mais cedo aí saia 16h e morava perto no almoço passava em casa. Meu filho foi amamentado até 9 meses de idade.

A 13... O que ajudou muito foi meu horário de trabalho ser em um turno só, permitindo nos demais horários estar com meu filho. Mesmo trabalhando em casa, estava com ele, podendo estar com ele e acompanhando seu desenvolvimento.

As trabalhadoras são funcionárias CLT, tem direito a 120 dias de licença e uma hora a menos do horário de expediente, no retorno, até os seis meses do bebê e foi observado que não havia local para armazenamento de leite e não tinha um ambiente favorável para a retirada do leite materno durante o expediente, dificultando o armazenamento para o bebê.

Acrescenta-se, assim, que a mulher precisa ser assistida e amparada para que possa exercer, a bom termo, o seu novo papel social: o de mulher-mãe-nutriz. Deve-se iniciar, no momento do pré-natal, o preparo da mulher para a lactação, resultando no sucesso da amamentação. Preconiza-se a orientação sobre as vantagens, para ela e para o bebê, sobre o uso de leite materno, técnicas de amamentação, com o objetivo de aumentar sua confiança e habilidade (Junqueira, 2019).

\section{Considerações Finais}

A pesquisa foi realizada com mulheres, jovens, com mais de 15 anos de escolaridade, em sua maioria com vida conjugal, com média de natalidade de um filho, realizaram o pré-natal no serviço público com atendimento médico e sem orientação sobre amamentação, e existem relatos que pré-natal com enfermeiros acontecia orientações sobre aleitamento. As mulheres apresentaram em média 4 meses de amamentação.

O enfermeiro tem papel fundamental no esclarecimento sobre possíveis dúvidas em relação ao período lactário, sendo que o aleitamento materno exclusivo, envolve questões sociais, biológicas e psicológicas, que devem ser acompanhadas desde o pré-natal, propiciando as mães o desenvolvimento da autoconfiança em amamentar e na expertise de superar dificuldades com o seu retorno ao trabalho.

A investigação sobre o retorno das mulheres trabalhadoras para os seus ambientes de trabalho, expõe uma série de dificuldades como falta de local adequado para retirada e armazenamento do leite materno.

O local da pesquisa, é uma Instituição de Ensino onde há muitas mulheres trabalhadoras em regime CLT, seria interessante para a saúde, e bem-estar de suas funcionárias e bebês, locais privativos e confortáveis para a realização da ordenha e do armazenamento correto do leite materno. Outro benefício empresarial importante é o oferecimento de creche.

Desenvolver uma rede de apoio nesse momento de retorno ao trabalho é indispensável para a mulher, poder contar com a ajuda do companheiro e de familiares no auxílio de tarefas domésticas e de apoio emocional, favorecendo o vínculo entre mãe e bebê, melhora na produção do leite materno, evitar o estresse e desmame precoce.

Inferimos que a pesquisa foi de grande relevância, pois foi possível perceber a necessidade da implantação de ações educativas voltadas para as mulheres trabalhadoras em relação à importância do aleitamento materno.

As estratégias utilizadas pelas mães para conseguirem manter o aleitamento foram a questão de morarem próximo ao trabalho, saírem uma hora mais cedo, realizar o armazenamento de leite, ter alguém da família ou um cuidador para ofertar o leite que a mãe deixou armazenado e a questão de trabalhar em um turno apenas. Sendo assim muitas mães conseguiram manter o aleitamento materno exclusivo.

O estudo tem por sua finalidade, trazer a importância vinculada a novas pesquisas e estudos com a temática ao aleitamento: mulheres contemporâneas de uma universidade privada do rio de janeiro. Tendo por seu papel principal, estratégias e medidas traçadas acerca da necessidade de um plano e ações de cuidados diferenciados, colocando em pauta a adequação e 
complexidade do paciente. Relevando também um bom conhecimento e as potenciais complicações no decorrer do tratamento, abordando da melhor forma com qualidade e agilidade, mantendo-se sempre como base o bem-estar.

\section{Referências}

Algarves, T. R., de Sousa Julião, A. M., \& Costa, H. M. (2015). Aleitamento materno: influência de mitos e crenças no desmame precoce/breastfeeding: myths and beliefs influence in early weaning. Saúde em Foco, 2(1), 151-167.

Alves, M. E. F., da Silva, E. C. A., de Andrade Nascimento, C. M. S., Pontes, E. D. S., Souza, M. L. A., Dantas, C. M. G., \& Silva, E. C. A. (2018). Malefícios trazidos pela interrupção do aleitamento materno exclusivo e a implementação do aleitamento artificial. International Journal of Nutrology, 11(S 01), Trab520.

Barreira, S. M. C., \& Machado, M. D. F. A. S. (2014). Amamentação: compreendendo a influência do familiar. Acta Scientiarum. Health Sciences, 26(1), 1120 .

Brasileiro, A. A., Possobon, R. D. F., Carrascoza, K. C., Ambrosano, G. M. B., \& Moraes, A. B. A. D. (2010). Impacto do incentivo ao aleitamento materno entre mulheres trabalhadoras formais. Cadernos de Saúde Pública, 26, 1705-1713.

Brown, A. (2017). Breastfeeding as a public health responsibility: A review of the evidence. Journal of Human Nutrition and Dietetics, 30(6), 759-770.

Callou, R. D. S. B. L. (2014). Mãe Trabalhadora: Como Manter A Amamentação Exclusiva? Revista Multidisciplinar da Saúde, 5(10), 70-83.

Caminha, M. D. F. C., Serva, V. B., Anjos, M. M. R. D., Brito, R. B. D. S., Lins, M. M., \& Batista Filho, M. (2011). Aleitamento materno exclusivo entre profissionais de um Programa Saúde da Família. Ciência \& Saúde Coletiva, 16, 2245-2250.

Colombo, L., Crippa, B. L., Consonni, D., Bettinelli, M. E., Agosti, V., Mangino, G., \& Mosca, F. (2018). Breastfeeding determinants in healthy term newborns. Nutrients, $10(1), 48$.

Costa, E. F. G. D., Alves, V. H., Souza, R. D. M. P. D., Rodrigues, D. P., Santos, M. V. D., \& Oliveira, F. L. D. (2018). Atuação do enfermeiro no manejo clínico da amamentação: estratégias para o aleitamento materno. Rev. pesqui. cuid. fundam. (Online), 217-223.

da Silva Dias, J., Costa, K., \& de Moura, M. R. W. (2014). A Atuação do enfermeiro na promoção do aleitamento materno através de ações educativas. Caderno de Graduação-Ciências Biológicas e da Saúde-UNIT-ALAGOAS, 2(1), 59-71.

da Silva Lima, P. F., Dos Santos, C. N., da Silva, M. V., \& de Lima Junior, A. A. (2017). A Atuação Do Enfermeiro Na Educação Em Saúde Com Ênfase No Apoio A Amamentação Exclusiva Até Os Seis Meses De Idade. Revista Saúde-UNG-Ser, 10(1 ESP), 45.

Davanzo, R. (2015, December). The promotion of breastfeeding and professional ethics. In Italian Journal of Pediatrics (Vol. 41, No. 2, pp. 1-1). BioMed Central.

Demitto, M. D. O., Silva, T. C. D., Páschoa, A. R. Z., Mathias, T. A. D. F., \& Bercini, L. O. (2010). Orientações sobre amamentação na assistência pré-natal: uma revisão integrativa.

de Souza, J., \& Valdivino, M. F. (2016). Mídias Sociais E Turismo: Uma Análise Do Evento" Natal Music" Utilizando A Técnica De Monitoramento Online. TURyDES, 9(20).

de Souza Minayo, M. C., Deslandes, S. F., \& Gomes, R. (2011). Pesquisa social: teoria, método e criatividade. Editora Vozes Limitada.

Flor, R. B., Damm, D. V., Almeida, A. R., de Sousa, A. P. S., \& Fernandes, A. G. (2019). Relato De Experiência: Grupo De Apoio Ao Aleitamento Materno Do Município De São Gonçalo. DEMETRA: Alimentação, Nutrição \& Saúde, 14, 43743.

Fragoso, A. P. R., \& Fortes, R. C. (2011). Fatores associados à prática do aleitamento materno entre nutrizes de um hospital público do Distrito Federal. J Health Sci Inst, 29(2), 114-8.

Gomes, C. S., \& Koifman, L. (2021). Amamentação: Uma questão (bio) ética? DIVERSITATES International Journal, 13(1).

Guex, G. D. R., \& Mattos, M. J. T. D. (2020). Helmintoses intestinais em caninos no Brasil: revisão de artigos publicados no período de 2013 a 2019. Revista Agrária Acadêmica. Imperatriz, MA. Vol. 3, n. 1 (jan./fev. 2020), p. 144-161.

Junqueira, T. L., Coelho, A. S. F., de Sousa, M. C., da Silva Louro, N., da Silva, P. S., \& Almeida, N. A. M. (2019). Gestantes que recebem informações de profissionais de saúde conhecem seus direitos no período gravídico-puerperal. Enfermagem em Foco, 10(4).

Lopes, W. C., Marques, F. K. S., Oliveira, C. F. D., Rodrigues, J. A., Silveira, M. F., Caldeira, A. P., \& Pinho, L. D. (2018). Alimentação de crianças nos primeiros dois anos de vida. Revista Paulista de Pediatria, 36, 164-170.

Nascimento, G. A. F., \& Bôas, R. V. V. (2016). Proteção da mulher: direito individual e social à igualdade de condições no mercado de trabalho e ao direito à maternidade. Conpedi Law Review, 1(6), 156-172.

Osis, M. J. D., Duarte, G. A., Pádua, K. S. D., Hardy, E., Sandoval, L. E. M., \& Bento, S. F. (2014). Aleitamento materno exclusivo entre trabalhadoras com creche no local de trabalho. Revista de Saúde Pública, 38, 172-179.

Picheth, S. F. (2016). Lógicas institucionais e estruturas discursiva: um estudo do maternati-grupo de gestante e mães.

Rollins, N. C., Bhandari, N., Hajeebhoy, N., Horton, S., Lutter, C. K., Martines, J. C., \& Group, T. L. B. S. (2016). Why invest, and what it will take to improve breastfeeding practices?. The lancet, 387(10017), 491-504. 
Research, Society and Development, v. 10, n. 11, e374101119599, 2021

(CC BY 4.0) | ISSN 2525-3409 | DOI: http://dx.doi.org/10.33448/rsd-v10i11.19599

Rocha, E. M. A., Macedo, L. K. M. de, Borges, L. V. A., Pinheiro, A. M. da C., Santos, R. da S., Conceição, H. N. da, \& Câmara, J. T. (2020). Aleitamento materno, amamentação tranquila e prazerosa: um relato de experiência. Research, Society and Development, 9(7), e155974006. https://doi.org/10.33448/rsdv9i7.4006

Santana, G. S., Giugliani, E. R. J., Vieira, T. D. O., \& Vieira, G. O. (2018). Factors associated with breastfeeding maintenance for 12 months or more: a systematic review is. Jornal de pediatria, 94, 104-122.

Sardinha, D. M., Maciel, D. O., Gouveia, S. C., Pamplona, F. C., Sardinha, L. M., Carvalho, M. D. S. B. D., \& Silva, A. G. I. D. (2019). Promoção do aleitamento materno na assistência pré-natal pelo enfermeiro. Rev. enferm. UFPE on line, 852-857.

Teixeira, M. A., Nitschke, R. G., \& da Silva, L. W. S. (2017). A prática da amamentação no cotidiano familiar-um contexto intergeracional: influência das mulheres-avós. Revista Kairós: Gerontologia, 14(Especial9), 205-221.

Vargas, G. S. A., Alves, V. H., Rodrigues, D. P., Branco, M. B. L. R., de Souza, R. D. M. P., \& Guerra, J. V. V. (2016). Atuação dos profissionais de saúde da estratégia saúde da família: promoção da prática do aleitamento materno. Revista Baiana de Enfermagem30,(2).

Victora, C. G., Bahl, R., Barros, A. J., França, G. V., Horton, S., Krasevec, J., \& Group, T. L. B. S. (2016). Breastfeeding in the 21st century: epidemiology, mechanisms, and lifelong effect. The Lancet, 387(10017), 475-490. 